\title{
Spatial and Typological Arrangement of the Population of Invertebrates in the Grass Cover of the Northeastern Altai S. M. Ponomareva ${ }^{a}$, P. Yu. Malkov ${ }^{b}$, V. V. Dubatolov ${ }^{c}$, S. E. Chernyshev ${ }^{c}$, A. V. Barkalov ${ }^{c}$, A. A. $\operatorname{Legalov}^{c}$, and S. V. Chesnokov ${ }^{c}$ \\ ${ }^{a}$ Altai State Natural Reserve, pr. Kommunisticheskii, 1, Gorno-Altaisk, 649000 Russia \\ ${ }^{b}$ Gorno-Altaisk State University, ul. Lenkina, 1, Gorno-Altaisk, 649000 Russia \\ ${ }^{c}$ Institute of Systematics and Ecology of Animals, Siberian Branch of the RAS, ul. Frunze, 11, Novosibirsk, 630091 Russia \\ E-mail: zm@eco.nsc.ru
}

\begin{abstract}
The major spatial changes in the communities of invertebrates in the grass cover of the Northeastern Altai and the factors determining these changes are revealed on the basis of multi-year accounts. The strength and general character of the connection between nonhomogeneity of population and environment are estimated.
\end{abstract}

DOI: $10.1134 /$ S199542550805007X

Investigation of the spatial arrangement of communities on the basis of analysis of data on the numbers and distribution of animals is one of the promising directions of zoogeographic research [1]. This line of investigation of animal populations is called factor zoogeography [2]. In terms of this discipline complex landscape zoogeographic investigations were carried out during several decades on the territory of the Northeastern Altai for various groups of animals [3-5], in particular, invertebrates [6-10]. Investigation of the invertebrate animal population inhabiting the grass level of vegetation (chortobionts) has not been carried out yet on this territory. Meanwhile, chortobionts as an important component of biocenoses attract the attention of zoologists. The choice of this group of invertebrate animals as the subject of zoogeographic investigation is also due to a relative simplicity of the methods of their record and the possibility to compare the data obtained by different recorders.

\section{MATERIALS AND METHODS}

Records of chortobionts were carried out in JuneAugust of 1998-1999. The submountain part of the province was studied in 1998, while medium- and high-mountain part was studied in 1999. In all the altitudinal belts within the province, 30 habitats were investigated (in the rank of landscape tracts). Records were carried out by sweeping with an entomological net. Five mows composed of a series of 50 sweeps were made in each habitat. When choosing places for sweeps we took into account the diversity of biotope conditions connected with the nonuniformity of the relief, different degrees of shadowing, wetting and anthropogenic impact. Sweeps were repeated every two weeks. The collected invertebrates were identified when possible to family. The abundance of chortobionts was calculated for 50 sweep movements of the net. The data obtained were averaged over the season. On the basis of average indices, Jacquard's coefficients were calculated [11] in the modification proposed by Naumov [12]; factor classification was carried out [13]. On the basis of the matrix of quotients of similarity for the distinguished group, a structural graph depicting the basic changes of the chortobiont population and environmental factors determining these changes was plotted using correlation pleiads [14]. However, comparison of data on the abundance of chortobionts in different altitudinal belts shows that it is much lower in the most optimal sub- and low-mountain landscapes than in the medium- and high-mountain ones. This altitudinal distribution did not agree with the existing ideas and contradicted the data obtained previously on the taxonomic groups of animals. Because of this, in 2005-2006 repeated records were carried out in the most typical tracts in different altitudinal belts. The taxonomic attribution of invertebrates in these collections was determined to the level of an order; the data on total abundance were then extrapolated to families using translation coefficients. The latter were calculated on the basis of the new data by comparing them with the previous ones for the years 1998-1999. Arbitrary indices of abundance for the years 2005-2006 were calculated using these coefficients. Then the average value was calculated using initial abundance indices and those obtained as a result of recalculation. On the basis of these average values, the factor classification was carried out using the above methods, a new structural graph was plotted, and the environmental factors correlating with the inhomogeneity of the communities of chortobionts were revealed.

To estimate the strength and generality of the relationship between the spatial changes of environmental factors and the population, we used a program of the linear qualitative approximation of the matrices of cou- 
pling [15]. When analyzing total abundance of chortobionts, we used the concept of background taxonomic groups selected by analogy with the background species. Groups with abundance higher than 1 individual per conversion unit were considered as such groups [16]. Also by analogy with the dominating species [17], the taxonomic groups accounting for more than $10 \%$ of total abundance were called dominating. The taxa comprising the first five ones when ranked in abundance were considered to be leading.

The performed investigations showed once more that it is desirable to carry out such a work within one season, as dictated by substantial oscillations of the number from one year to another, which is especially well-expressed for invertebrates and is due to the action of various abiotic and biotic factors including weather conditions. Some cases are known when, under the action of extremely high temperatures, the number of forest insects drastically increased during the subsequent year [18]. This situation may have also occurred in the case under consideration. For instance, in the summer of 1998 temperature was unusually high for the Northeastern Altai, while the rainfall was small. Next 1999 year, when mows were made in the medium- and highmountain parts of the province, their results turned out to be much higher than those in the low- and submountain part. We came to the conclusion that the data obtained for the medium and high-mountain part are overestimated (rather than the data for the low- and submountain part are underscored) after having obtained the results of mows for the low- and submountain part in 2005; those results showed similar values with the primary data for this territory. In 2006, mows were made simultaneously in the low-, medium- and highmountain landscapes. The abundance of chortobionts in the low-mountain part again turned out to be close to the previous values while the values obtained for the medium- and high-mountain parts were noticeably lower than those obtained in 1999. Because of this, all the calculations were carried out using conventional averages for 1998, 1999, 2005 and 2006; the data for the latst two years were calculated for the level of abundance during these years, over the fractions of taxonomic groups for the years 1998 and 1999.

\section{ALTITUDE-DEPENDENT CHANGES OF POPULATION}

Changes in the average indices of total abundance of chortobionts over the altitudinal belts occur with sharp swings (Fig. 1). From the submountain forest-steppe belt to the low-mountain forest one, the abundance first increases by a factor of two, reaching here the maximum level; then it declines steadily upward: by a factor of 2 in the medium-mountain forest belt, and by a factor of 5 , in the subgolets belt. The difference in abundance between the subgolets and golets belts is insignificant. Such a type of distribution, that is, with the maximum abundance in one of the forest subbelts and a decrease in the indices above and below this level, was called rhomb-like [19]. The maximum abundance here is due to the optimal combination of conditions, especially warmth and humidity, providing the high productivity of biocenoses. The rhomb-like type of abundance changes is also characteristic of other groups of animals examined within this province, in particular for daytime lepidopterous insects, reptiles, birds, and mammals. A pyramidal type is characteristic of a number of invertebrates inhabiting the soil stage (Ixodidae and flea of small mammals, ants, Carabidae), as well as for Am-

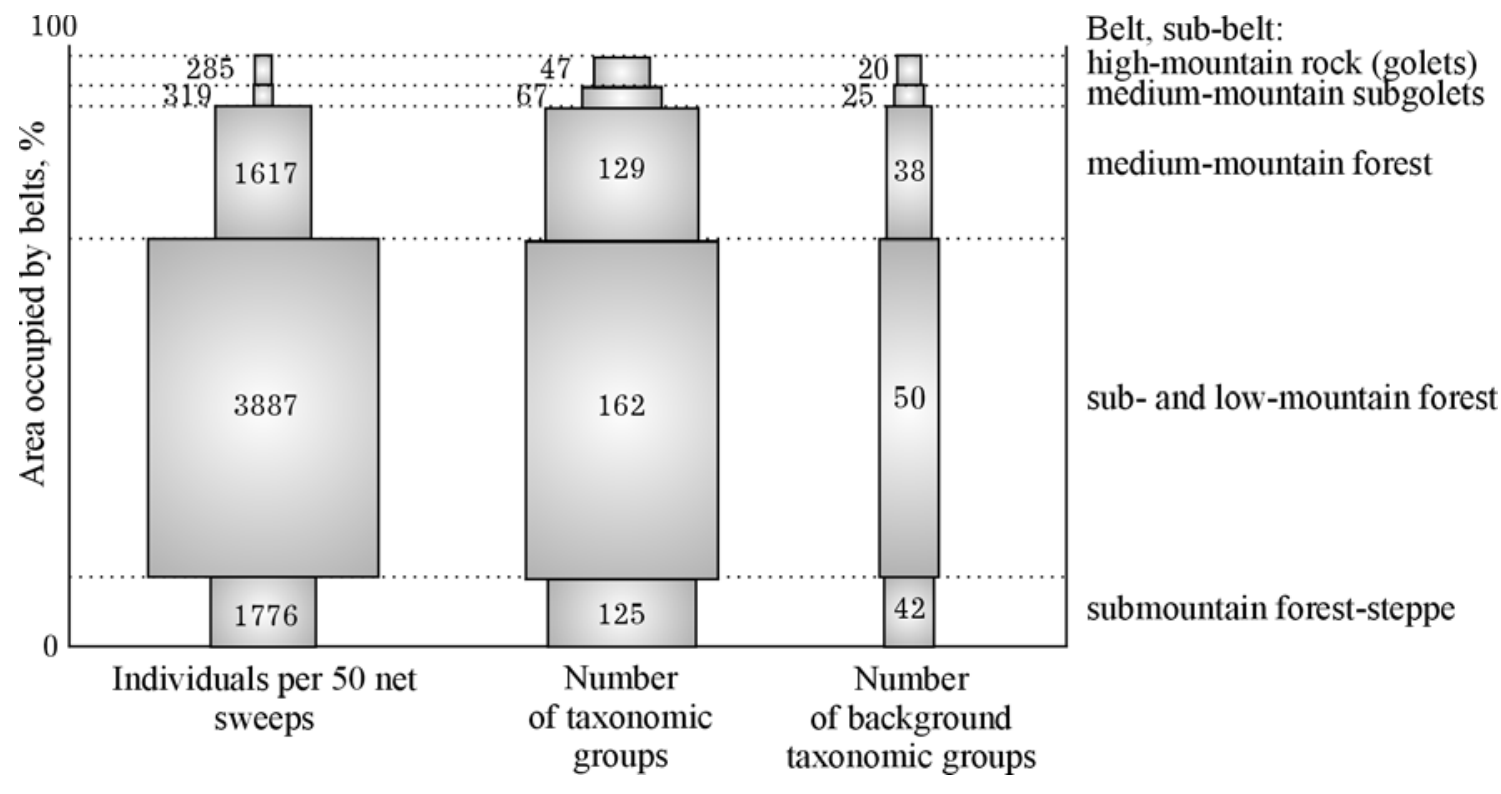

Fig. 1. Altitudinal-belt changes of the total abundance and taxonomic richness of the population of invertebrates in the grass cover of the Northeastern Altai. 
phibia, that is, the maximum abundance is observed in the submountain forest-steppe belt, with a more or less gradual decrease while absolute heights increase. Such a character of index changes is likely to be connected with decreased warmth and in part with increased shadowing, which is more important for these animals than for the majority of vertebrates. The altitudinal changes of the number of species of all animal groups under analysis except Carabidae have a rhomb-like character. A strictly pyramidal type of changes of the number of species of Carabidae is connected with their higher sensitivity to the mentioned environmental factors.

In the forest-steppe belt, along with the flies from the anthomiid family (Diptera, Anthomyiidae) and mirids (Hemiptera, Miridae), the leading group also includes typical representatives of open habitats - locust (Orthoptera, Acrididae), however, their fraction is relatively small (5\%). Unlike them, antomiids are leaders also in the low-mountain forest subbelt; however, their abundance decreases substantially (from 19 to 9\%). The abundance of mirids changes in a similar manner, but they as leaders go up to the medium-mountain forest subbelt. Permanent leaders of all the altitudinal belts except the forest-steppe one are leafhoppers (Homoptera, Cicadellidae). Their participation is especially significant in the medium-mountain forest subbelt and in the high-mountain rock belt where they absolutely dominate (31 and 38\%). High wetting of the mediummountain forest subbelt determined the leading position of hygrophilous froghoppers (Homoptera, Aphrophoridae). With a rise to the medium-mountain rock belt, chrysomelids (Coleoptera, Chrysomelidae) and ichneumons appear among the leaders along with froghoppers. The same composition is also recorded in the high-mountain golets belt.

Changes in the taxonomic richness over the belts occur in a similar way. From the forest-steppe belt, where 1225 taxa were recorded, to the low-mountain forest subbelt, their number increases to 162 , then in the medium-mountain forest subbelt it decreases again (129). At the subgolets belt it decreases by a factor of $2(67)$. The smallest number of taxonomic groups is characteristic of the high-mountain golets belt (47).

The background richness changes from one belt to another generally in a similar way as the total abundance but with smaller drops of values.

In general, a common trend is observed in the changes of abundance and taxonomic richness over altitudinal belts. The indices under comparison decrease as the absolute altitude increases. This is most clearly exhibited for the rise to the medium subgolets and high-mountain golets belts. The maximum values are characteristic of the low-mountain forest subbelt, which is connected with the optimal combination of warmth and wetting there.

\section{CLASSIFICATION OF POPULATION}

General regularities of the spatial variability of chortobiont population are depicted in the idealized classification scheme shown below. The scheme is based on groups of communities distinguished by automatic classification. After the first partitioning, 12 groups (classes) of population were obtained; 5 of them were composed of several versions and 7 comprised solitary samples. When idealizing in agreement with the accepted explanation of a certain combination of population versions, the community of medium-mountain open woodland with yernik on golets, which forms a separate class having some similarity only with the population of stony tundra and cedar taiga, was included into the same group as the latter. Then the version of the population of birch and pine submountain valley forests was united with the communities of chortobionts of sub- and low-mountain light coniferous parvifoliate and parvifoliate forests because according to the results of partitioning it had equipotent links with this group and the population of low-mountain coniferous forests and a weaker connection with the community of low-mountain bogs. In addition, the version of the population of low-mountain inhabited areas previously combined with the communities of low-mountain coniferous forests was distinguished as a separate group. At last, 11 classes remained. After the name of a type or a class of population, the first five taxonomic groups leading in abundance are given in parentheses; their average abundance is indicated, as well as total indices of population density, taxonomic general and background richness.

1. Submountain-low-mountain type of population (mirids - 43, antomiid flies - 35, leafhoppers - 25, ants Hymenoptera, Formicidae - 20, aphids Aphidinea - 11;283; 98; 53).

Classes of population:

1.1 - low-mountain floodplain osiers and fields (mirids - 80, aphids - 34, crab spiders Thomisidae and acridoid grasshoppers - 19 each, leaf beetles 17 ; 332; 98; 41);

1.2 - submountain valley meadows (acridoid grasshoppers - 44, corn-flies Diptera, Chloropidae 37 , leafhoppers - 32, mirids - 27, ants - 19; 250; 68; $33)$;

1.3 - low-mountain and submountain light coniferous parvifoliate and parvifoliate forests (ants - 35, mirids - 29, leafhoppers - 16, ichneumons and antomiid flies - 14 each; 262; 145; 47);

1.4 - low-mountain forests: coniferous and those with the participation of dark coniferous species (antomiid flies -44 , mirids -20 , leafhoppers -15 , ants -14 , dipterans $\left.{ }^{1}-7 ; 170 ; 98 ; 29\right)$;

\footnotetext{
1 Representatives of the dipteran order not identified to a family.
} 
1.5 - low-mountain fallow meadows (leafhoppers - 209, mirids - 150, acridoid grasshoppers 56 , antomiid flies - 36, dipterans - 17; 628; 63; 35);

1.6 - submountain bogs (mirids - 12, curculios Coleoptera, Curculionidea - 11, acridoid grasshoppers - 9, wolf spiders Lycosidae - 7, froghoppers Homoptera, Aphrophoridae - 6; 115; 59; 26);

1.7 - low-mountain bogs (froghoppers - 55, raft spiders Pisauridae - 39, jumping spiders Salticidae 27 , mirids - 19, ants - $17 ; 288 ; 75 ; 31$ );

1.8 - submountain inhabited areas (antomiid flies -317 , mirids -76 , corn-flies -16 , ground bugs - Hemihtera, Lygaeidae - 12, dipterans - 9; $526 ; 62 ; 27)$;

1.9 - low-mountain inhabited areas (antomiid flies - 89, mirids - 36, leafhoppers - 29, dipterans and acridoid grasshoppers - 11 each; 258; 69; 25).

2. Medium-mountain type of population (medium mountain region, except open woodland on rocks and cedar taiga, with the penetration into high-mountain regions over yernik tundras; leafhoppers - 89, mirids 24 , leaf beetles and dipterans - 17 each, froghoppers - $13 ; 284 ; 130 ; 36)$.

3. High-mountain type of population (stony tundras with the penetration into medium-mountain open woodland on rocks and into the cedar taiga; leafhoppers - 13, dipterans - 8, leaf beetles - 7, ichneumons - 6, coccinellids - Coleoptera, Coccinellidae $-5 ; 79 ; 61 ; 16)$.

The types of population reflect a connection between the nonhomogeneity of chortobiont communities with absolute altitudes of the territories. Partitioning of the sub- and low-mountain type into classes is controlled by the composition of forest-forming species, water-logging and anthropogenic action.

The map of chortobiont population shows that about $2 / 3$ of the province is occupied by complicated differentiated sub- and low-mountain type of population, the rest of the area is shared by the medium- and highmountain types (Fig. 2). The boundaries of type occurrence coincide with the province partition into the suband low-mountain and medium-mountain taiga parts, which exhibits a similarity with the spatial partitioning of the Northeastern Altai with respect to the ant population [20]. The latter is due to the effect of the difference in warmth amount for the habitats, which is more essential for this group of animals than for vertebrates. The partition of the sub- and low-mountain type into classes of population for chortobionts reflects to a definite extent the landscape structure of this part of province. The homogeneity of population in the medium-mountain taiga part of the region is connected with low warmth amount, which is determined by absolute altitudes of the territory and shadowing with the crown of dark coniferous trees.

A comparison of the classification of chortobiont population with the classifications of other investigated groups of animals showed the lowest degree of differentiation of chortobiont population. This may be explained by a higher (in the taxonomical aspect) level of consideration, which allows one to reveal only the most general differences in the population.

\section{SPATIAL AND TYPOLOGICAL STRUCTURE OF POPULATION}

The spatial and typological structure of animal population is understood as the general character of its territorial changes revealed for the morphological similarity of communities, without taking into account their coupling at localities [15].

In the vertical graph built up for the threshold of relationship significance of 28 units of similarity (Fig. 3), the vertical row composed of classes $1.1 ; 1.3 ; 2$ and 3 , illustrates the main trend in changes of the population, connected with the changes in warmth amount and wetting of habitats, determined by absolute altitudes. Other classes demonstrate deviations from the main trend due to changes in the composition of forest-forming species, water-logging and anthropogenic action in the form of building-up, fallowing and multiple mowing. In the three-factor space, the trends plot in three transverse planes. The main trend and deviations from it, distinguished as a result of the action of fallowing, composition of forest-forming species and mowing, are depicted on the plane perpendicular to the reader's view, while the versions of populations of bogs and inhabited areas are placed in two other planes crossing the first one at different angles.

The highest abundance of individuals over the main trend is characteristic of class 1.1 , which is composed of the population of submountain fields, meadow copses and low-mountain floodplain osiers. Comparatively high abundance of chortobionts here is due to the high amount of warmth and sunniness, as well as the large amount of grass phytomass which is characteristic of open habitats. At the same time, agrocenoses included in this class are characterized by monoculture character and relative biotopic uniformity, which is responsible for rather low taxonomic richness.

Insignificant decrease in the abundance of chortobionts was observed when passing to the next class of sub- and low-mountain type (1.3) uniting the population of light coniferous parvifoliate and parvifoliate forests of low- and submountain regions, which may be connected with shadowing with tree crowns and some rarefaction of the grass cover. In general, favorable hydrothermal conditions, diversity of the communities united in this class (8) and the mosaic character of habitats provided the highest taxonomic richness among all the classes.

With the rise to the communities of the taiga habitats of medium-mountain type of population, the abundance of chortobionts increases insignificantly in comparison with the previous class. This is due to the high produc- 

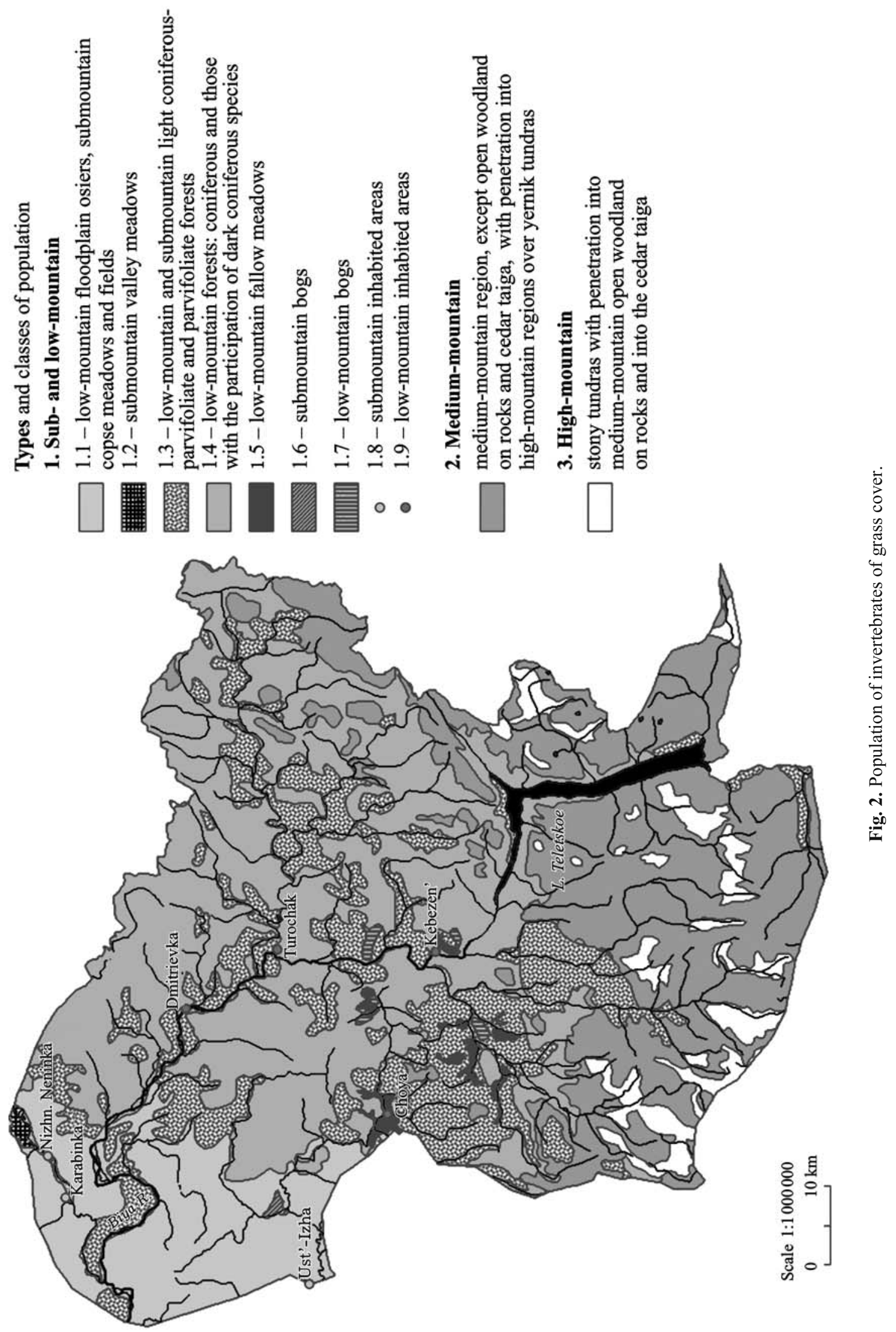


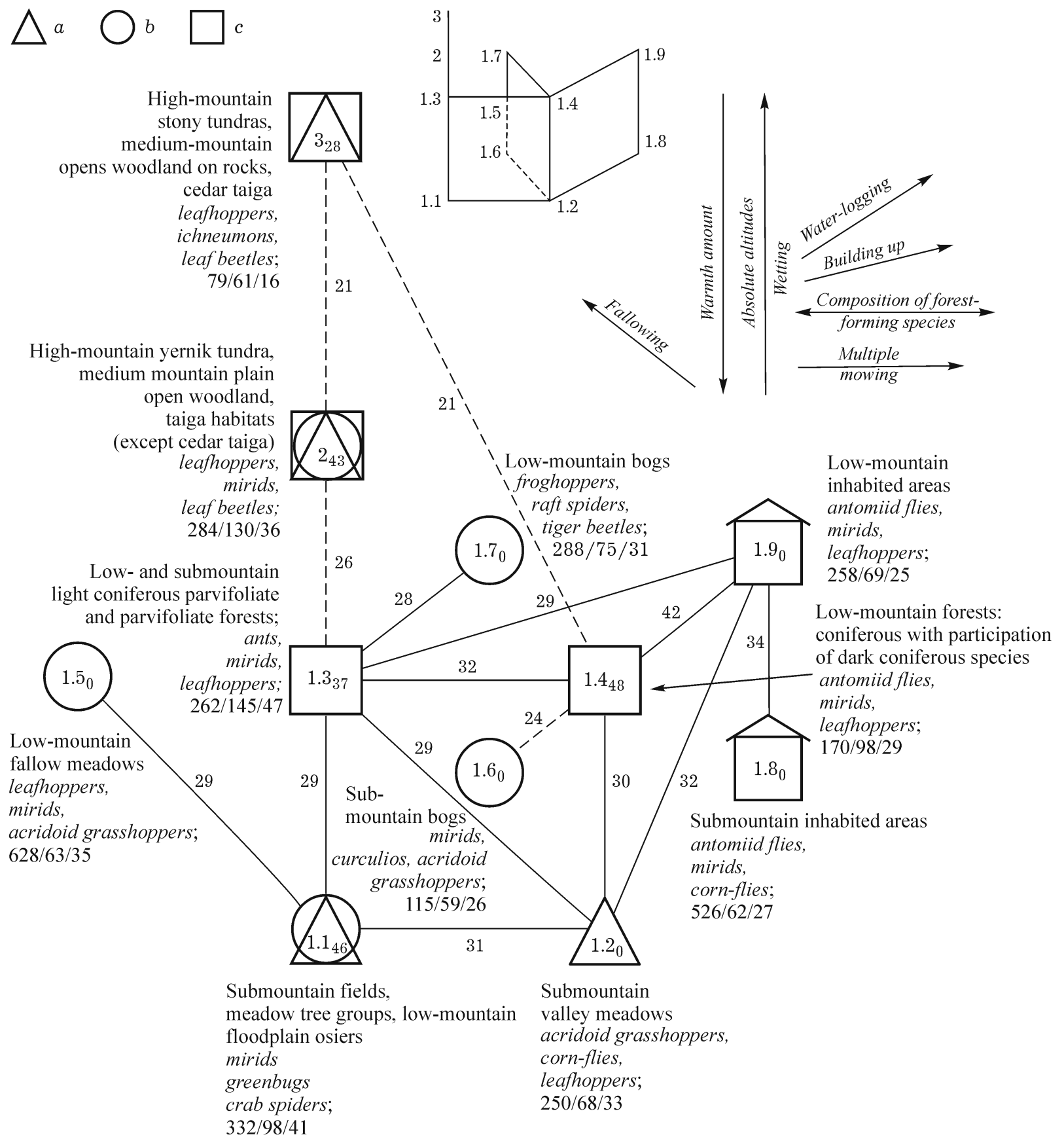

Fig. 3. Spatial and typological structure of the population of invertebrates of the grass cover of the Northeastern Altai (according to the data of 1998, 1999, 2005 and 2006). Population: $a$ - open habitats of low productivity; $b$ - habitats of open regions alternating with forested ones; $c$ - forests; the numbers of distinguished groups are shown by figures inside the symbols; indices near these figures indicate the intragroup similarity. The symbols connected with a continuous line have over-threshold similarity, those connected with a dash line above- threshold one. The numbers near these lines are estimations of the intergroup similarity. Arrows in the scheme indicate the direction in which the manifestation of an environmental factor increases. Near the symbols, there are a list of the habitats with the population related to this group, three taxa with the highest abundance, total abundance (individuals per 50 net sweeps), number of marked and background taxa.

tivity of the phytocenoses of the lower part of the taiga medium-mountain region (fir-birch, aspen-birch forests and cuts in the place of cedar-abies taiga), where high wetting in combination with low shadowing provide good heating of the ground layer. The taxonomic diver- sity is somewhat lower here, but due to the above reasons it remains rather high.

A sharp decrease in the abundance and taxonomic richness occurs in the transition to high-mountain type of population uniting the communities of high-moun- 
tain tundra, medium-mountain open woodland on rocks, and cedar taiga. Small amount of warmth and rocky soil in these habitats are responsible for suppression and rarefaction of the grass cover, which substantially decreased the abundance and taxonomic diversity of chortobionts.

So, we can clearly observe the effect of altitudinal zoning. The value of total abundance depends on the amount of warmth in combination with wetting and shadowing, connected with the forest state. The taxonomic richness is determined by the diversity of phytocenoses and the mosaic character of tracts, whose communities are included in the taxon composition.

A deviation of the community of submountain valley meadows (class 1.2) from the main trend is owing to the effect of multiple mowing, which decreases the abundance and taxonomic richness in comparison with the communities of physionomically similar biotopes of submountain fields, meadow copses and low-mountain floodplain osiers (class 1.1).

The effect of the composition of forest-forming species is expressed in the appearance of the population of low-mountain pine, abies-pine-birch forest and dark taiga (class 1.4). High shadowing due to coniferous trees provided a specific composition and low diversity of the grass cover in these tracts. For example, the major part of grass in a pine forest is represented by ferns. It should be noted that these habitats are situated near inhabited areas and the grass cover in them is subjected to a definite degree of trampling and eating away by cattle, which could not but affect the abundance and diversity of chortobionts. The vicinity of an inhabited area may have also affected the taxonomic composition. The leading family in abundance in the community of this class are antomiid flies, which are more characteristic for anthropogenic landscapes.

Another direction in the changes of the chortobiont population under the action of fallowing is observed when passing from submountain open and mosaic habitats (class 1.1) to low-mountain fallow meadows (class 1.5) which represent strongly degraded meadows formed in place of fallows. Similar to other agrocenoses, here we observe the low taxonomic diversity and high abundance of chortobionts owing mainly to the participation of two families - leafhoppers and mirids.

Depletion of the chortobiont communities of bogs (classes 1.6 and 1.7) was caused by the effect of water-logging, which affected the taxonomic diversity. A combination of water-logging with forest growth provided the difference in the appearance of the population of sub- and low-mountain bogs forming separate classes and having no significant relationship. The features characteristic of bushy submountain bogs (class 1.6) are specific hydrothermal regime connected with high illumination, and the presence of meadow grass in the vegetation, which resulted in the prevalence of mesophilic invertebrates here (mirids, weevils, acridoid grasshoppers) over hygrophilic ones. However, in gen- eral, these habitat conditions are not favorable for any of them, as depicted in the total abundance and taxonomic richness, which are lower here than in other classes of sub- and low-mountain population. The hydrothermal regime of forest low-mountain bogs due to a smaller amount of warmth and stronger shadowing makes optimal conditions for hygrophilic invertebrates (froghoppers, raft spiders and tiger beetles).

The effect of building-up provided changes in the population of inhabited areas (classes 1.8 and 1.9). Low taxonomic richness is characteristic of them, similarly to other communities deviating from the main trend. Total abundance in large submountain inhabited areas may be the highest among all the versions of population but more than a half of it is composed of the representatives of one family - antomiid flies. In the low-mountain inhabited areas, with the same composition of leaders, total abundance is two times lower, perhaps due to a decrease in the amount of warmth.

So, the character of spatial nonhomogeneity of the population of invertebrates of the grass cover is affected largely by the amount of warmth and wetting, which are determined by the absolute altitude of a territory. This is clearly seen as a decrease in the abundance and diversity of chortobionts from submountain regions to high mountains in the main row of the graph. In the medium- and high-mountain regions of the province, the importance of these factors is so high that the effect of others is almost not observed. In the sub- and low-mountain part, the nonhomogeneity of chortobiont population is also determined by the composition of forest-forming species, water-logging and anthropogenic action. The latter provides a decrease in the taxonomic richness and prosperity of only few families.

A comparative analysis of the spatial structures obtained for all the data and materials collected during the years 1998-1999 showed that the fluctuations of the number of invertebrates had an effect only on the fractional character of the partitioning of spatial changes of communities. The main trend correlating with the changes in absolute altitudes, as well as the most sharp deviations from it are revealed independently of the differences between the data collected during different years. For example, the structural graph obtained on the basis of the primary data (Fig. 4) illustrated three main trends which were due to changes in absolute altitudes, coupled amount of warmth and the effect of water-logging and building-up. The communities of mediumand high-mountain landscapes are united into the same groups as those comprised on the basis of the entire set of data. The communities of the sub- and low-mountain parts of the province are divided into six classes, two of which became part of the main trend and four became a deviation from it. The differences in the versions connected with the effect of the composition of forestforming species, fallowing and mowing are significant only for the united data; the effect of the low-mountain 


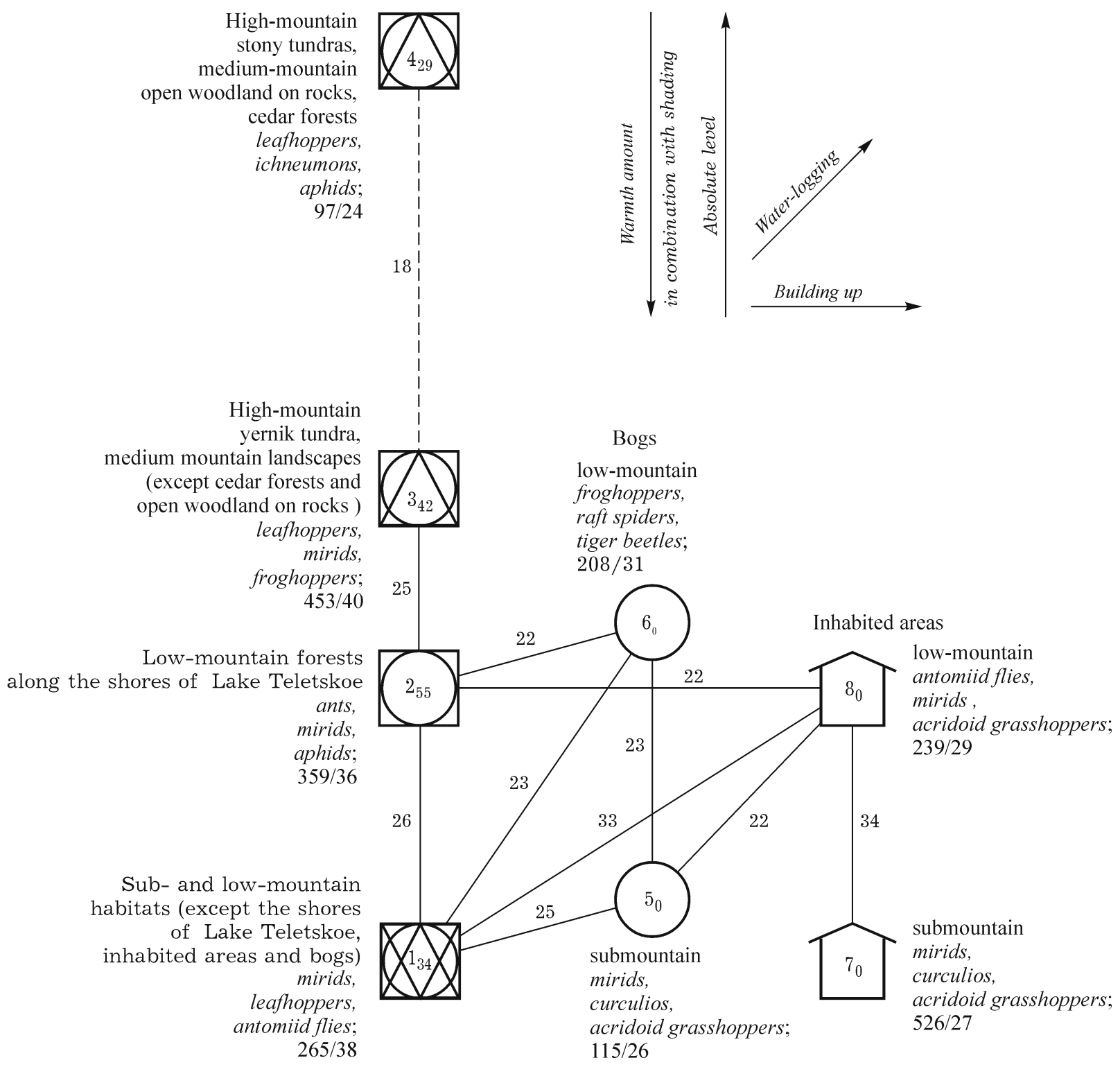

Fig. 4. Spatial and typological structure of the population of invertebrates of the grass cover of the Northeastern Altai (according to the data of 1998-1999). Designations of the chortobiont population are the same as in Fig. 2.

forests along the shores of Teletskoe Lake were significant only for first years of observations.

\section{SPATIAL AND TYPOLOGICAL ARRANGEMENT OF THE POPULATION}

The spatial and typological arrangement of the animal population is understood as the general character of its spatial nonhomogeneity (spatial structure) and a set and interconnection of environmental factors determining it [21]. The calculations showed that the greatest effect on the differentiation of the chortobiont population is that produced by absolute altitudes and the composition of forest-forming species (29 and 31\% of the recorded variance of the similarity coefficient matrix for the communities, respectively). The effect of water-logging is much lower (4\%); so is the effect of building-up (3\%). The factor of the least significance is fallowing; it accounts for only $2 \%$ of variance. All the factors may explain $46 \%$ of the variance of similarity coefficient matrix. $67 \%$ of variance are connected with al the factors and regimes (the coefficient of multiple correlation is 0.82 ).

The list of the main environmental factors affecting the nonhomogeneity of chortobiont population is very similar to that for other groups of animals. The most important among them are the amount of warmth and the related factors (absolute altitudes, shadowing), as well as the composition of forest-forming species [19]. Among the specific features of organization, one may 
stress the effect of fallowing on the nonhomogeneity of chortobiont population.

\section{CONCLUSION}

The investigation allowed us to make the following conclusions.

1. The altitudinal-belt changes of total abundance, taxonomic and background diversity of chortobionts have a rhomb-like character, that is, their values initially increase (with an increase in absolute altitudes of the territory up to the low-mountain region) and then decrease (to high-mountain tundra).

2 . The spatial nonhomogeneity of chortobiont population is to the highest extent due to the effect of correlated factors: absolute altitudes of the territory, amount of warmth and wetting, which, in turn, determine the altitudinal belt of vegetation. In addition, a substantial effect on the differentiation of chortobiont population is caused by the composition of forest-forming species. Its action is expressed through shadowing and the species-specific composition of grass cover. Less significant is the effect of water-logging and anthropogenic action (building up, fallowing,, and multiple mowing).

3 . The set of the revealed factors and regimes may be considered rather complete because the information content of the notions of structure-forming factors of environment and natural-anthropogenic regimes in general accounted for $67 \%$ of the variance of population, which corresponds to the correlation coefficient equal to 0.82 .

The investigations were supported by the Integration Project of SB RAS No. 56 and by the Departmental Target Program Higher School 2006-2008 (RNP 2.11.5218).

The data used as the basis for the paper were collected with the participation of U. Yu. Veryaskina, O. P. Vozniichuk and K. V. Toropov, spider identification was carried out by D. V. Logunov and G. N. Azarkina. Subsequent statistical treatment of the data was carried out with assistance of L. V. Pisarevskaya and I. N. Bogomolova using the programs of the Database of the ISEA SB RAS. Yu. S. Ravkin took a direct part in the interpretation of treatment results. The authors express deep gratitude to all the mentioned researchers.

\section{REFERENCES}

1. P. P. Vtorov and N. N. Drozdov, Biogeography of Continents (Prosveshchenie, Moscow, 1974) [in Russian].

2. Yu. S. Ravkin, in Proceedings of 7th All-Union Zoogeogr. Conf. (Nauka, Moscow, 1989), pp. 264-267 [in Russian].
3. Yu. S. Ravkin, Birds of Northeastern Altai (Nauka, Siberian Branch, Novosibirsk, 1973) [in Russian].

4. I. V. Luk'yanova, in Problems of Zoogeography and History of Fauna (Nauka, Siberian Branch, Novosibirsk, 1980), pp. 255-273 [in Russian].

5. K. V. Grazhdan, K. V. Toropov, and U. Yu. Veryaskina, in Animal Realm of Altai-Sayan Mountain Country (Gorno-Altaisk, 1999), pp. 43-50 [in Russian].

6. Yu. V. Drozdov, in Nature of Foci of Tick-Borne Encephalitis in Altai (Nauka, Siberian Branch, Novosibirsk, 1967), pp. 21-30 [in Russian].

7. V. F. Sapegina, in Nature of Foci of Tick-Borne Encephalitis in Altai (Nauka, Siberian Branch, Novosibirsk, 1967), pp. 38-46 [in Russian].

8. P. Yu. Malkov, "Spatial-Temporal Organization of Population of Diurnal Lepidoptera (Lepidoptera, Rhophalocera) of Northeastern Altai," Candidate's Dissertation iin Biology (Inst. Syst. Ecol. Animals, SB RAS, Novosibirsk, 2002).

9. S. V. Chesnokova and L. V. Omel'chenko, Sibirskii Ekologicheskii Zh., 11 (4), 481 (2004).

10. S. B. Ivanov, "Spatial-Temporal Organization of Population of Ground Beetles (Cleoptera, Carabidae) of Northeastern Altai," Candidate's Dissertation in Biology (Novosibirsk, 2007) [in Russian].

11. P. Jacquard, Bull. Soc. Vaund. Sci. Nat. 38 (69), 130 (1902).

12. R. L. Naumov, "Birds in Foci of Tick-Borne Encephalitis of Krasnoyarsk Krai," Candidate's Dissertation in Biology (Moscow, 1964) [in Russian].

13. V. A. Trofimov and Yu. S. Ravkin, in Quantitative Methods in Ecology of Animals (Leningrad, 1980), pp. 113115 [in Russian].

14. V. P. Terent'ev, Vestnik LGU, No. 9, 137 (1959).

15. Yu. S. Ravkin, Spatial Organization of Population of Birds of Forest Zone (West and Central Siberia) (Nauka, Siberian Branch, Novosibirsk, 1984) [in Russian].

16. A. P. Kuzyakin, Uchen. Zap. MOPI Im. N. K. Krupskoi, 109, 1 (1962).

17. V. N. Beklemishev, Biocenotic Basics of Comparative Parasitology (Nauka, Moscow, 1952) [in Russian].

18. M. K. Meteleva, in Entomological Studies in Northern Asia, Proceedings of 7th Interregional Meeting of Entomologists of Siberia and Far East (in Siberian Zool. Conf.), 20-24 September 2006 (Novosibirsk, 2006), pp. 363-365 [in Russian].

19. Yu. S. Ravkin, S. V. Chesnokova, V. A. Yudkin, et al., Northeastern Altai: Animals and Environment (Annotated Atlas) (Izd. SO RAN, Novosibirsk, 2008) [in Russian].

20. Yu. S. Ravkin, S. V. Chesnokova, V. A. Yudkin, et al., Sibirskii Ekologicheskii Zh. 12 (6), 955 (2005).

21. Yu. S. Ravkin, V. L. Kupershtokh, and V. A. Trofimov, in Birds of Forest Zone of Ob Region, Ed. by Yu. S. Ravkin (Nauka, Siberian Branch, Novosibirsk, 1978), pp. 253269 [in Russian]. 